\title{
MEDIAÇÃO E MEDIADORES NOS FLUXOS TECNOCULTURAIS CONTEMPORÂNEOS
}

\section{LA MEDIACIÓN Y LOS MEDIADORES EN LOS FLUJOS TECNOCULTURALES CONTEMPORÁNEOS}

\author{
Marco Antônio de Almeida - marcoaa@ffclrp.usp.br \\ Doutor em Ciências Sociais pela Universidade Estadual de Campinas \\ (UNICAMP). Professor do Programa de Pós-graduação em Ciência da \\ Informação da Universidade de São Paulo (PPGCI-ECA/USP).
}

\section{RESUMO}

Introdução: As Tecnologias de Informação e Comunicação estabeleceram uma rede global na qual sociedades com distintos modos de vida e histórias se entrecruzam, causando um profundo impacto nos modos de vida cotidiana dos indivíduos. Decorrem daí desafios inéditos para se pensar as ações de mediação da informação - particularmente nesse território híbrido caracterizado pela convivência e intersecção dos processos culturais \& tecnológicos.

Objetivo: Analisar as mudanças sociais relacionadas ao terreno das práticas informacionais e culturais contemporâneas, buscando compreender aspectos dos processos culturais e de enraizamento social da tecnologia. Mapear alguns desafios para a mediação hoje, envolvendo questões tecnológicas, culturais e políticas. Discutir o campo das Humanidades Digitais como novo território de mediações.

Metodologia: Revisão bibliográfica, observações de campo.

Resultados: São apresentadas discussões clássicas e contemporâneas sobre a temática, e também a discussão intermediação versus desintermediação. Algumas ações de mediação são apresentadas como insumo para reflexão.

Conclusões: As conexões entre cultura e tecnologia se tornam cada vez mais estreitas, e não podem ser analisadas de forma ingênua. $O$ termo Humanidades Digitais, embora ainda seja uma etiqueta genérica, surge como um campo interdisciplinar disposto a dar guarida às reflexões e às práticas suscitadas pelas mudanças decorrentes da introdução das tecnologias digitais no universo da cultura e das Unidades de Informação e Cultura. 
Palavras-chaves: Mediação. Cultura. Tecnologias de Informação e Comunicação. Humanidades Digitais.

\section{INTRODUÇÃO}

Há alguns anos, quando comecei a estudar o conceito de mediação, elaborei uma revisão bibliográfica sobre o tema, buscando esclarecer as origens e definições do conceito, especialmente a partir das contribuições dos campos das Ciências Sociais e da Comunicação (ALMEIDA, 2008). Pude chegar a duas conclusões a partir desse processo. A primeira, a de que o termo era intrinsecamente polissêmico, derivando seu significado do contexto em que era utilizado - tanto das concepções teóricas a que se vinculava como à prática cultural, comunicacional ou informacional a qual se aplicava. Como observou Davallon (2007), parece impraticável uma definição consensual de mediação, um conceito plástico que estende suas fronteiras para dar conta de realidades muito diferentes entre si - o que acrescenta mais níveis de complexidade à análise dos fenômenos dispostos sob esse rótulo.

A segunda conclusão foi a de que até então havia se cristalizado em parcela substantiva da bibliografia a concepção de que as ações de mediação não seriam o estabelecimento de uma simples relação entre dois termos de mesmo nível, mas que em si mesmas seriam produtoras de um "algo a mais", ou de um estado mais satisfatório em relação às condições iniciais. De alguma forma, a mediação "agregaria valor" aos processos culturais, informacionais ou comunicacionais, gerando ganhos em termos de conhecimento aos sujeitos envolvidos. Nesse sentido, as atividades de mediação seriam quase que naturalmente valorizadas, pelo potencial implícito de "geração de valor cultural". Por outro lado, na contracorrente dessa perspectiva, determinados autores enxergariam nos processos de mediação uma imposição de valores, um "adestramento" das competências receptivas dos sujeitos. Assim, passariam a valorizar as mudanças tecnológicas que possibilitam a "desintermediação", a possibilidade dos sujeitos exercitarem sua autonomia na rede (LÉVY, 2000; FOURIE, 2001).

Um dos objetivos desse texto é tentar compreender como se passou de um pólo a outro em relação a essas perspectivas e juízos que se constituíram acerca da mediação - particularmente nesse território híbrido caracterizado pela convivência e 
intersecção dos processos culturais \& tecnológicos. Para tal, analisamos num primeiro momento as mudanças sociais relacionadas ao terreno das práticas informacionais, culturais e sociais, buscando compreender alguns aspectos dos processos culturais e de enraizamento social da tecnologia. Consideraremos o diferencial entre "mediação" como conceito sociológico geral que caracteriza os processos sociais, do conceito especializado de "mediação" como prática institucional, bem como a ideia de "desintermediação" proposta por alguns autores. A seguir, mapearemos alguns dos desafios para a mediação hoje, envolvendo desde questões de formação e técnico-institucionais, como também questões tecnológicas e políticas. Nesse sentido, exploraremos algumas das possibilidades vislumbradas pelas propostas de constituição do campo das "Humanidades Digitais", instância interdisciplinar híbrida que conjugaria cultura e tecnologia e, a partir de alguns exemplos, teceremos considerações acerca das mediações dentro/fora das instituições, com especial ênfase às Unidades de Informação e Cultura (UICs).

\section{CULTURA, TECNOLOGIA, MEDIAÇÕES}

O sentido de alguns conceitos acompanha as transformações sociais ao longo da história, agregando novas camadas de significados que buscam dar conta de compreender a realidade cambiante. Algumas dessas transformações, no caso específico da cultura contemporânea, vinculam-se aos processos de globalização, às transformações na vida cotidiana e às novas formas de construção da subjetividade (HALL, 2005). O papel das tecnologias de informação e comunicação (TICs) é central nesse processo. Foram as TICs que estabeleceram uma rede global na qual sociedades com distintos modos de vida e histórias se entrecruzam. Esse novo ambiente causou um profundo impacto nos modos de vida cotidiana dos indivíduos, trazendo choques entre as culturas locais e fluxos culturais globalizados. Stuart Hall chama a atenção para uma série de deslocamentos do cotidiano das culturas, decorrentes de mudanças globais na reorganização sócio-econômica das sociedades "pós-modernas" ou "pós-industriais". Mas ele atenta especialmente para o papel dos meios de comunicação tradicionais e das TICs na disseminação de informação e conteúdos simbólicos. A "centralidade da cultura" na contemporaneidade assenta-se fundamentalmente em quatro dimensões: 1- a ascensão de novos domínios, instituições e tecnologias associadas às indústrias 
culturais; 2- a cultura vista como força de mudança social a partir dos influxos da globalização; 3- as modificações culturais pelas quais passou a esfera do cotidiano; 4- a importância da cultura na formação das identidades individuais e sociais. (HALL, 1997)

A complexa configuração contemporânea do sistema cultural terminou por tornar necessário um sofisticado aparato de informação, que envolve recursos (físicos e humanos) cada vez mais amplos. George Yúdice (2006) problematiza a utilização do termo cultura no mundo contemporâneo, na medida em que ela passa a ser considerada como um recurso, não se limitando, contudo, ao simples papel de mercadoria. No atual contexto, os recursos culturais, assim como os naturais, não comportam uma exploração pura e simples. A cultura pensada como recurso envolve o gerenciamento, a conservação, o acesso, a distribuição e o investimento. Administrar os recursos culturais, visando atingir distintos objetivos, tornou-se um desafio para Estados, empresas e movimentos sociais.

O que procuramos destacar é que, cada vez mais, a cultura, associada à tecnologia, torna-se central na dinâmica das sociedades contemporâneas. A produção simbólica na assim chamada "sociedade da informação" cresce exponencialmente, por parte dos grandes conglomerados de mídia, mas, graças às TICs, também por parte de governos em seus diversos níveis, grupos, coletivos artísticos, indivíduos, comunidades, associações, etc. Nesse processo são geradas novas formas de solidariedade, de identidade, de ação social, assim como novas fontes de recursos econômicos. A presença de recursos humanos capacitados tanto no plano dos processos culturais, como no domínio de habilidades tecnológicas, torna-se um elemento de fundamental importância para o sucesso dessas iniciativas.

As comunidades virtuais em rede vêm se popularizando de forma a abarcarem uma variedade de possibilidades comunicacionais e formas de experimentação da realidade, resultando em diferentes graus de experiência e de tipos de apropriações que delas resultam. As TICs mudam de forma rápida e profunda a forma como nos comunicamos com outras pessoas e nos relacionamos com os diversos fluxos informacionais locais e globais. A apropriação dessas tecnologias é continuamente reinventada, conforme possibilidades são exploradas e outras caem em desuso, de maneira que seus limites comunicacionais são modificados e expandidos de forma constante. 
Por outro lado, a ideia de rede remete, com uma excessiva naturalidade, para um universo de liberdade e abundância informacional ao alcance dos indivíduos e grupos. Trata-se de uma mistificação apoiada numa falsa ideia de "neutralidade" das tecnologias: não há rede sem escolha, sem organização, sem hierarquia, já que os conhecimentos não existem fora de um contexto social, nem se reorganizam de maneira aleatória. Competências comunicativas, culturais, educacionais e cognitivas são fundamentais para que os indivíduos contextualizem a informação e a utilizem o que remete à velha questão das desigualdades sociais.

A desigualdade social não é apenas uma questão referente à partilha adequada dos recursos, mas de participação na determinação das oportunidades de vida tanto individuais como coletivas. A premissa subjacente a essa afirmação é a de que a capacidade de acessar, adaptar e criar novos conhecimentos por meio das TICs é decisiva para a inclusão na chamada "Sociedade da Informação". Para Mark Warschauer (2006), acesso é decisivo para a inclusão social. Existem dois elementos de acesso mais comumente lembrados em relação a essa discussão: equipamentos e conectividade. Porém, por si só não são suficientes quando pensamos em acesso num sentido mais abrangente, considerando seus aspectos socioculturais, o que torna necessário refletir acerca de um terceiro elemento, que é o letramento. Ainda que os acessos ao computador e à conectividade sejam fundamentais, o que é mais importante não é tanto a disponibilidade do equipamento ou da rede de internet, mas sim "a capacidade pessoal do usuário de fazer uso desse equipamento e dessa rede, envolvendo-se em práticas sociais significativas." (WARSCHAUER, 2006, p. 64)

$\mathrm{O}$ acesso e o letramento estão intimamente ligados aos avanços da comunicação humana e aos meios de produção do conhecimento. Warschauer (2006, p. 66) lembra que, embora o senso comum "defina o letramento como habilidade individual de ser capaz de ler e escrever", na verdade os estudiosos preferem uma definição mais abrangente, que considera os contextos sociais das práticas associadas ao letramento. Assim, o letramento não é uma habilidade neutra em valor e isenta de contexto; pelo contrário, a condição de ser letrado sempre se refere a ter domínio sobre os processos, por meio dos quais a informação culturalmente significativa está codificada. No caso da internet, nota-se que o conhecimento está na rede, mas que é um conhecimento codificado; "trata-se antes de saber onde está a informação, como buscá-la, transformá-la em conhecimento 
específico para fazer aquilo que se quer fazer". (CASTELLS, 2003, p. 266). Repousa, portanto, nesse tipo de "competência", o que define, efetivamente, a idéia de uma "divisória digital", tal como apontada por Castells: o elemento de divisão social mais importante nesse momento é a capacidade educativa e cultural de utilizar a internet. Embora o mote do "aprender a aprender" já tenha quase se tornado um clichê, ele expressa essa competência de localizar e utilizar efetivamente o conhecimento, competência desigualmente distribuída e relacionada à origem social, à origem familiar, ao nível cultural e ao nível de educação.

Desenham-se assim questões relativas à proteção da informação, à problemática do poder, aos limites de toda e qualquer comunicação, à saturação da informação gerada pela expansão das redes, às competências culturais e intelectuais dos indivíduos e grupos para lidar com esse universo. E finalmente mas não por último - remete também à necessidade da mediação cultural e da informação e ao papel estratégico dos mediadores nos fluxos tecnoculturais que caracterizam a contemporaneidade.

A noção de mediação no campo das Ciências Sociais geralmente encontra-se ligada às chamadas "teorias da ação". Nesse sentido, "ações sociais são sempre parte de sistemas mais amplos e de processos de compreensão intersubjetiva, o que introduz a questão do papel do agente ('mediação humana') nos processos através dos quais as ações são coordenadas." (OUTHWAITE e BOTTOMORE, 1996, p. 03). A comunicação e o intercâmbio de informações são fenômenos que fornecem fundamentos para a ação, sempre situada e analisada na esfera da vida pública (vale lembrar aqui as implicações que Habermas retira desse fato em sua teoria da ação comunicativa). Nessa perspectiva, as mediações são as conexões que se estabelecem entre as ações sociais e as motivações (individuais/coletivas). São processos de interlocução ou de interação entre os membros de um grupo ou comunidade, que permitem o estabelecimento e a sustentação dos laços de sociabilidade, constituindo assim, numa perspectiva habermasiana, o mundo da vida. A linguagem e a ação comum são os fatores privilegiados de mediação. (ALMEIDA, 2008; HABERMAS, 1984, 1989)

Extrapolando essa concepção sociológica, veremos que a incorporação da mediação como atividade ao "mundo dos sistemas" (usando a terminologia habermaseana) implicará numa polissemia de concepções, relacionadas à diversidade dos contextos institucionais em questão. Assim, segundo Caune (2014, 
p. 73), outra perspectiva "considera a mediação um conjunto de práticas sociais, que se desenvolvem em setores institucionais variados e que visam construir um espaço determinado pelas relações que nele se manifestam". O conceito de mediação recobre, portanto, atividades diferenciadas, que vão das concepções correntes de "atendimento ao usuário" às ações de um agente cultural em uma dada instituição museu, biblioteca, arquivo, centro cultural -, à construção de produtos destinados a introduzir o público num determinado universo de informações e vivências (educação, arte, lazer, por exemplo), à elaboração de políticas de capacitação ou de acesso às tecnologias de informação e comunicação, à mediação tecnológica proporcionada por ferramentas informacionais em rede (portais, sites, weblogs), etc. Assim, "instituições como a escola, a mídia ou, ainda, os empreendimentos culturais podem ser analisados em função das relações interpessoais que desenvolvem e do sentido que eles ajudam a compartilhar". (CAUNE, 2014, p. 73) Trata-se, portanto, de um conceito de enorme plasticidade e flexibilidade, que quando pensado no plano das instituições, praticamente impossibilita uma única definição consensual, na medida em que os sentidos das práticas que recobre derivam de realidades distintas entre si. (ALMEIDA, 2008; DAVALLON, 2007)

Embora no plano das instituições conceito de mediação seja bastante polissêmico e complexo, vale destacar seu valor estratégico para abordar as relações entre mudança social e mudança tecnocientífica. Diversos pensadores reforçam essa perspectiva, como, por exemplo, Bruno Latour (2008), Michael Callon (2004), Bernard Miège (2009). A apropriação sociocultural da tecnologia envolveria, na perspectiva de Miège, uma série de processos. Em conjunto, estes processos podem ser entendidos como "lógicas sociais" da informação-comunicação, que, embora possuam de certa forma uma dinâmica própria, independente das TICs, recebem delas impulsos dinâmicos que as vão conformando no decorrer do tempo.

A perspectiva de Miège aponta a importância de tentar enlaçar e combinar os níveis "macro" e "micro" da análise num mesmo movimento de compreensão do real. De um lado, considerar a dimensão política, econômica e social das atividades infocomunicacionais que implicam nas inovações e experimentações de novos suportes e ferramentas. De outro lado, não perder de vista a articulação entre as TICs e a produção de mensagens e sentido, bem como o "enraizamento" social das tecnologias traduzido, entre outras, pela atividade dos usuários-consumidores no aperfeiçoamento dos dispositivos e ferramentas. Com relação a esse último aspecto, 
o autor utiliza o termo "enraizamento" social das TICs com cautela, alertando para o risco de soar um pouco ambíguo, ao dar a entender que a tecnologia seria algo produzido num lugar fora do social e para lá transplantado posteriormente - o que seria contraditório com sua perspectiva. $\mathrm{Na}$ realidade, ele pretende apontar com esse termo os fatores que levam os indivíduos a se apropriarem das tecnologias, incorporando-as ao seu cotidiano, num processo que muitas vezes implica na combinação da reconfiguração de novos usos para as ferramentas e na criação de novos hábitos e atitudes sociais. (MIÈGE, 2009).

De um modo geral, a concepção de mediação como ação educativa que se estabeleceu hegemonicamente prioriza algumas modalidades de informação, de tipos de leitura e de práticas de intermediação cultural legitimadas pelo status quo, em detrimento de outras, que valorizariam o estabelecimento de vínculos mais orgânicos dos sujeitos com o conhecimento prático, racional e técnico. Enquanto essa primeira concepção se satisfaria com a assimilação e não com a apropriação da cultura artística e científica, desencadeando mediações e leituras esvaziadas, parece-nos fundamental refletir sobre este ponto, quando se tem em vista uma real inserção dos sujeitos na cultura.

O ponto de vista assumido por Miège valoriza, portanto, os processos de constituição da autonomia dos sujeitos e, em alguma medida, em que pesem os referenciais teóricos muito distantes entre si, podemos estabelecer um diálogo com alguns postulados de Jürgen Habermas $(1984,1989)$ acerca dessa questão. Essa autonomia surge, para Habermas, no exercício de uma racionalidade aplicada e ao mesmo tempo construída no curso de uma ação comunicativa. Devemos lembrar que, para Habermas, a racionalidade não é expressão de alguma entidade abstrata, nem atributo da sociedade como um todo, mas um processo que, a qualquer instante, pode ser desencadeado pela disposição e capacidade dos parceiros da interação, de sustentar discursivamente suas posições mediante argumentos. Assim, a capacidade discursiva é traduzível precisamente na disposição a praticá-la, construindo aquilo que Habermas, num empréstimo à Linguística, denomina de competência comunicativa. Os atores são, portanto, portadores de processos de aprendizado: são produtos de um processo de formação de sujeitos, considerados como tais por terem adquirido, nesse processo, consciência - capacidade reflexiva que permite ao sujeito apreender o mundo na sua relação com ele (HABERMAS, 1989; ALMEIDA, 2012). Os fenômenos culturais, embora vivenciados pelos 
indivíduos e grupos, só obtém suas significações a partir de um quadro histórico e social, como observa Caune, e assim "o acesso à compreensão dos fatos culturais passa pela análise das manifestações perceptíveis e das relações de significação que elas estabelecem com aquele que as recebe". (CAUNE, 2014, p. 61)

\section{MEDIAÇÃO X DESINTERMEDIAÇÃO}

Nesse momento da argumentação parece-nos estratégico introduzir alguns pontos do debate acerca da contradição intermediação versus desintermediação.

Dominique Wolton (2003) propõe uma reflexão acerca do tipo de informação produzida pelos sistemas técnicos e seus usos. Em outras palavras, a relação/oposição entre a facilidade de acesso e competência para a assimilação e a manipulação de informações e conhecimentos. Wolton chama a atenção para os intermediários e seu papel de facilitadores ao acesso da informação e do conhecimento. Esses mediadores (que para ele seriam os professores assim como os documentalistas) teriam um papel importantíssimo: "começa-se a perceber a força de emancipação e de progresso que existe no estatuto dos intermediários. A emancipação não reside mais em suprimir os intermediários, mas, ao contrário, em reconhecer o seu papel". (WOLTON, 2003, 136)

Por outro lado, autores como Pierre Lévy (2000) e Ina Fourie (2001) propõem o conceito de desintermediação, introduzindo outras nuances no cenário desenhado por Castells. Para Lévy, ocorre um processo de descentralização, que graças à internet e ao apelo comunicacional dos usuários, enfraquece os meios tradicionais de comunicação como mecanismo de mediação. O autor está refletindo acerca do controle das informações, de sua filtragem e disseminação seletiva pelos mediadores institucionais tradicionais presentes numa concepção de sociedade de comunicação de massas - desde estações de TV, rádios e editoras até escolas e bibliotecas (LÉVY, 2000). A interatividade, agilidade e o protagonismo dos usuários a partir do surgimento da internet modifica essa condição. Na verdade, estes mesmos usuários agora podem ser seus próprios mediadores, uma vez que a internet solidificaria sua autonomia frente as suas necessidades informacionais e culturais. Contrastando com a tipologia comunicacional anterior, caracterizada pela distribuição de informação de "um para todos", a WEB possibilita agora que essa distribuição passe a ser de "todos para todos". 
São duas posições antagônicas. Para os críticos da desintermediação, como Wolton (2003), o puro acesso aos mais variados tipos de informação não implica numa potencialização da capacidade de construção do conhecimento: o desenvolvimento das competências intelectuais relacionadas às estratégias de busca, compreensão e apropriação da informação ainda é o fator mais importante, e os mediadores seriam os facilitadores desse processo. Em contrapartida, Lévy (2000) ressalta que os processos anteriores à desintermediação eram simplórios e despersonalizados, ao contrário dos novos processos resultantes das atividades dos próprios indivíduos, muito melhor sintonizados às suas necessidades e interesses. Fourie (2001) ocupa uma posição intermediária entre esses dois polos: reconhece que com a ampliação do acesso à internet seja inevitável que as pessoas realizem suas próprias buscas de informação. Sistemas de informação e comunicação vêm sendo desenvolvidos de forma mais "amigável", proporcionando maior independência e autonomia a seus usuários, caracterizando, portanto, um crescente grau de desintermediação. Por outro lado, ainda assim não descarta o papel dos mediadores:

A mudança das exigências do usuário final, seu acesso à informação e suas necessidades, provocaram uma mudança paralela no papel dos mediadores. Isto é importante para os mediadores que tratam de melhorar o acesso social à informação de qualidade. Se mais usuários finais são capazes de assumir a responsabilidade de suas próprias buscas de informação - ou ao menos algumas delas - a atenção dos mediadores pode orientar-se para outras questões importantes. (FOURIE, 2001, p. 281, tradução nossa).

O contexto que permite a construção de um conceito como o de desintermediação é o do desenvolvimento de produtos e serviços informacionais cada vez mais sofisticados e, ao mesmo tempo, de relativa facilidade de uso por parte dos indivíduos. É o caso dos grandes mecanismos de busca, particularmente o Google, criado em 1998, que se tornou a referência hegemônica inclusive entre profissionais e pesquisadores da informação. (GIORDANO; BIOLCHINI, 2012) O Google, por meio de seu algoritmo de busca, o PageRank, baseou-se no modelo de citação acadêmico para aferir a "importância" das páginas da internet, tornando-se posteriormente a inspiração de mecanismos semelhantes. No atual cenário da sociedade da informação, o Google e seus congêneres contribuiriam decisivamente 
para o processo de desintermediação, cumprindo assim o papel de guiar com precisão e segurança os usuários às informações que eles necessitam - ou não?

Para autores como Eli Pariser (2012), essa ideia é ilusória e, no limite, potencialmente cerceadora das possibilidades de autonomia abertas pela internet. Ao analisar o processo de personalização pelo qual passa a internet, fruto de uma mudança nos aparatos de mediação da rede, Pariser tenta desconstruir dois lugares-comuns acerca dessas tecnologias e de suas aplicações na internet. De um lado, a ideia de que elas eliminariam a intermediação, proporcionando uma experiência "direta" do usuário com o universo da informação. De outro lado, a promessa de que proporcionariam resultados mais "satisfatórios", por estarem mais afinadas às características de cada usuário.

O autor afirma que as mediações não apenas permanecem, como se multiplicam, graças aos "filtros invisíveis" que são o cerne dos mecanismos de busca. Esse processo, segundo ele, nos encerra numa "bolha de filtros", bastante confortável, pois aparentemente se baseia em nossos gostos e afinidades para realizar seu trabalho. Entretanto, segundo Pariser, "por não escolhermos os critérios que os sites usarão para filtrar os diversos assuntos, é fácil intuirmos que as informações que nos chegam através de uma bolha de filtros sejam imparciais, objetivas, verdadeiras". (PARISER, 2012, p. 15) O que ele demonstra, no decorrer do livro, é que essas informações - especialmente por se atrelarem aos interesses corporativos das grandes empresas e à lógica de consumo do mundo contemporâneo - não são neutras: "na verdade, quando as vemos dentro da bolha, é quase impossível conhecer seu grau de parcialidade." (PARISER, idem) São esses filtros invisíveis presentes nos motores de busca que possibilitaram o surgimento da internet "personalizada". Apesar de reconhecer as vantagens desse formato de internet, sua preocupação reside no fato de que esse processo é invisível para os usuários, e totalmente fora de controle: "a internet talvez saiba quem somos, mas nós não sabemos quem ela pensa que somos, ou como está usando essas informações" (PARISER, 2012, p. 193). Para o autor, a tecnologia que deveria nos proporcionar mais controle sobre nossas vidas, aos poucos o está retirando.

As observações de Pariser demonstram que as conexões entre cultura e aplicações tecnológicas tornam-se cada vez mais imbricadas, não admitindo mais análises ingênuas que partem do senso comum da "neutralidade" das tecnologias. Isso não significa tornar-se um "apocalíptico" ou um "tecnófobo", mas considerar as 
implicações sociais, culturais e econômicas que a adoção de qualquer tecnologia apresenta. Como já observou Neil Postman (1994, p. 17) a respeito, as tecnologias tanto fazem novas coisas como desfazem as antigas: assim, "os usos de qualquer tecnologia, são determinados, em grande parte, pela estrutura da tecnologia em si, isto é, que suas funções resultam de sua forma". O que nos deveria levar, sempre, a alguns questionamentos: a quem a nova tecnologia dará maior poder e liberdade? Qual o seu impacto sobre a vida cotidiana das pessoas comuns? Qual é o preço a ser pago pela mudança tecnológica?

\section{AS HUMANIDADES DIGITAIS: UM ESPAÇO PRAXIOLÓGICO PARA A MEDIAÇÃO}

Do ponto de vista das novas perspectivas e abordagens relacionadas a estes temas, duas questões particularmente despertam minha atenção. A primeira delas tem a ver com a ideia de constituição de um novo campo de conhecimento e reflexão interdisciplinar que congregaria muitas destas inquietações, 0 das chamadas "Humanidades Digitais". A outra questão seria relacionada às discussões acerca da apropriação da informação, dos aspectos de empoderamento (empowerment) presentes nas ações e políticas culturais, e traduzidos em iniciativas e experimentos destinados a criar competências/habilidades no tocante ao uso dos recursos proporcionados pelas TICs. Ou, em outros termos, os aspectos educativos de ações de mediação cultural e informacional comprometidas com a noção de autonomia dos sujeitos.

Há muito mais uma solução de continuidade do que de ruptura das bibliotecas às modernas Unidades de Informação, na medida em que elas foram se adaptando às séries de mudanças tecnológicas e socioculturais que se sucederam em termos de uma história de longa duração. Por outro lado, definir hoje o que seria uma unidade de informação torna-se cada vez mais difícil, dada a variedade e complexidade de perfis possíveis que as mesmas podem adotar. Nesse sentido, a centralidade cada vez maior da dimensão cultural no mundo contemporâneo joga um papel proeminente. Podemos afirmar que, cada vez mais, tendem a organizarem-se como UICs - Unidades de Informação e Cultura -, espaços desencadeadores e centralizadores de políticas culturais e da informação. Diferenciam-se de outros espaços culturais de pura expressão cultural (teatro, 
cinema, galeria de arte) que, entretanto, podem estar contemplados como partes de uma UIC.

Desse modo, o aparecimento do campo de conhecimento denominado "Humanidades Digitais" é um sintoma e uma consequência desse largo processo; não é exclusividade do mundo anglo-saxão, embora seja nele que tenha se consolidado inicialmente (DOUEIHI, 2010; SVENSSON, 2010); por outro lado, começa a se consolidar no mundo ibero-americano (GALINA-RUSSELL, 2011; PONS, 2013). As convergências e afinidades entre as práticas e reflexões deste campo em relação à Ciência da Informação são evidentes, e estudos exploratórios visando mapear possíveis pontes e intercruzamentos configuram-se como estratégicos na atual conjuntura.

Para falar do campo emergente das "Humanidades Digitais", parece-me importante um pequeno preâmbulo histórico. Mudanças sociais e tecnológicas desde sempre determinaram modificações e adaptações das unidades de informação (independentemente de sua denominação), isso quando não foram diretamente determinantes em seu surgimento. O longo processo histórico de transformação e especialização pelo qual passaram as unidades de informação no passado levou à especialização das mesmas (bibliotecas, arquivos, museus, centros de documentação). As Tecnologias de Informação e Comunicação (TICs) vêm gerando novos e acelerados processos de transformação nesse campo: as diferenciações não cessam de existir enquanto funções/vocações de cada unidade, mas elas tendem a convergir em novos espaços híbridos. Também contribui para esse processo a centralidade que a cultura passa a ocupar na sociedade contemporânea, expressa em novas formas de políticas públicas, relações de mercado e reflexões acadêmicas.

Podemos recordar as mudanças nos suportes da informação: dos rolos e papiros da Biblioteca de Alexandria e congêneres do mundo antigo, à convivência dos mesmos com o formato de códex que vai se impondo a partir da constituição das bibliotecas monásticas na Europa Medieval. Posteriormente, a convivência de livros manuscritos, incunábulos e, finalmente, livros impressos, que vão se tornar a referência das bibliotecas e destinar os demais à seção de "obras raras". A aceleração das mudanças tecnológicas de final do século XIX e no correr do século XX aprofundam a multiplicação de suportes que passam a conviver nas bibliotecas (e também nos arquivos): fotografias, microfilmes, cassetes de áudio, rolos de filmes, 
fitas VHS, CDs, DVDs ... até chegarmos aos suportes/repositórios digitais, e às concepções de biblioteca digital.

O mesmo pode ser dito em relação à mudança nos regimes de leitura: de um lado, com a Modernidade e seus ideais iluministas, observa-se um progressivo aumento de leitores, decorrente dos processos conjugados de ampliação da oferta de fontes escritas, políticas educacionais e necessidades socioeconômicas de qualificação da mão-de-obra. De outro lado, um processo que se inicia antes ainda, de diversificação dos regimes de leitura e dos tipos de leitor a eles associados, como observam, entre outros, Peter Burke $(2008,2012)$ e Lucia Santaella (2004). Há, assim, a passagem de uma leitura intensiva (em especial, da Bíblia) a uma leitura extensiva (várias fontes e autores); de uma leitura concentrada e isolada a uma leitura de signos urbanos e, posteriormente, a uma leitura hipertextual que se consolida com a navegação nas telas, consolidando e ilustrando a passagem do leitor de um único suporte ao leitor de múltiplos suportes (analógicos e/ou digitais).

Finalmente, temos as mudanças econômico-sociais: deslocamento do papel do conhecimento no contexto das sociedades ocidentais, num largo processo de constituição, valorização e aplicação da ciência, de um lado, e de outro, na valorização do acesso à informação para a participação cidadã na vida pública. $A$ isso vem somar-se, mais contemporaneamente, outro processo, que é o de "centralização" cada vez maior da cultura no mundo contemporâneo (HALL, 1997). Todos esses processos, em larga medida, influenciaram na constituição e mudança das instituições do conhecimento (BURKE, 2008; 2012).

O termo "Humanidades Digitais", embora seja ainda uma etiqueta genérica, surge como um campo interdisciplinar disposto a dar guarida às reflexões e às práticas suscitadas pelas mudanças decorrentes da introdução das tecnologias digitais no universo da cultura e das Unidades de Informação e Cultura brevemente descritas acima. Nesse campo das "Humanidades Digitais" caberia distinguir vários territórios e enfoques (SVENSSON, 2010; GALINA-RUSSELL, 2011; DOUEIHI, 2010; PONS, 2013), desde tecnologias aplicadas às disciplinas classicamente enquadradas nas áreas tradicionais de Humanas, como também novas áreas de pesquisa e ensino, como os estudos da internet e as apropriações socioculturais das TICs. Desse modo, como campo acadêmico, as "Humanidades Digitais" transcendem a exclusiva preocupação com a utilização de ferramentas informáticas aplicada às humanidades, configurando também questões teóricas e filosóficas 
próprias. Como observa Milad Doueihi, trata-se de todo um "entorno digital", compreendido como "conjunto constituído pelas tecnologias e pelos instrumentos digitais, pelos usos e práticas que estes tornam possíveis, e pelo marco jurídico que supostamente os governa" (DOUEIHI, 2010, p. 37). Assim, devido precisamente à natureza desse entorno, "as práticas culturais digitais postulam sérios problemas à maneira de proceder clássica, onde a lei se esforça por alcançar a técnica” (idem). Além disso, as Humanidades Digitais se configuram não só como objeto de pesquisas, como também, cada vez mais, como um âmbito de ensino na graduação e na pós-graduação, e de intervenção da Universidade e de seus pesquisadores nos processos sociais. Projetos de pesquisa-ação, ou parcerias com instituições e movimentos sociais, são bastante frequentes nessa área emergente.

\section{AÇÕES E POLÍTICAS CULTURAIS DE MEDIAÇÃO}

O outro ponto relativo às questões que envolvem os processos de mediação é a presença, bastante marcante em alguns casos, de processos de acesso/divulgação-circulação da informação e de processos de acesso/apropriaçãoformação de competências técnico-culturais. Em outras palavras: a preocupação, de um lado, de fazer circular a informação e torná-la pública, especialmente a informação cultural; e, de outro, a preocupação em capacitar e formar os atores envolvidos (individuais e coletivos), traduzida numa ampla gama de oferta de cursos, oficinas, seminários, projetos abertos, etc. Para ilustrar este ponto, mencionarei algumas experiências a partir de minha experiência de pesquisa com as políticas culturais brasileiras e nos centros culturais espanhóis na cidade de Madrid.

A Casa do Leitor, com uma superfície total superior a oito mil metros quadrados, localiza-se no grande espaço cultural que é o Matadero de Madrid. Trata-se de uma unidade de informação e cultura que faz dos leitores e da leitura seus protagonistas fundamentais. Organiza exposições, conferências, cursos formativos, oficinas de criação, ciclos de música, cinema e artes cênicas, junto a pesquisas aplicadas. Além de proporcionar o encontro do público em geral com o mundo dos profissionais, do público jovem e infantil com o público adulto, estende o conceito de leitura, partindo do pressuposto que não há manifestação cultural que, para seu conhecimento e desfrute, não requeira um exercício pleno de leitura. 
O aspecto que mais me chamou a atenção nas atividades da Casa do Leitor, durante as visitas que realizei, foi a perspectiva radical de atuação institucional focada na leitura, mas que subverteu a discussão ao privilegiar o suporte dos $e$ readers e das redes em relação ao tradicional suporte do livro. O suporte impresso continua ocupando espaço dentro das discussões, exposições e pesquisas levadas a cabo pela Casa do Leitor, mas na relação com seus usuários o suporte de leitura utilizado é o outro. As implicações desse giro radical afetaram desde a cultura administrativa-institucional da fundação responsável pela gestão da unidade, que teve que requalificar seus funcionários e contratar outros com perfis bastante diferenciados, até as concepções de acervo, de curadoria e de ação cultural utilizadas até então, quando as atividades de mediação da leitura centravam-se no suporte livro. Isto foi feito incorporando novos processos de gestão e organização, novas atividades - envolvendo processos de qualificação e formação de mediadores e de usuários -, como também mantendo e adaptando atividades já existentes como os círculos de leitura, agora desenvolvidos de forma híbrida, presencial-virtual, utilizando ferramentas de redes sociais.

Outra experiência espanhola é o Medialab-Prado, um programa da área de Artes, Esportes e Turismo da prefeitura de Madrid. O Medialab-Prado se concebe como um laboratório cidadão de produção, investigação e difusão de projetos culturais que explora as formas de experimentação e aprendizagem colaborativa que surgiram com as redes digitais. Entre seus objetivos estão: a- habilitar uma plataforma aberta que acolha e permita aos usuários configurar, alterar e modificar os processos de investigação e produção; b- dar sustentação a uma comunidade ativa de usuários por meio do desenvolvimento desses projetos colaborativos; coferecer diferentes formas de participação que permitam a colaboração de pessoas com distintos perfis (artístico, científico, técnico), níveis de especialização (expertos e principiantes) e graus de implicação.

Para viabilizar e alcançar estes objetivos, o Medialab-Prado oferece um espaço permanente de informação, escuta e encontro, atendido por mediadores culturais que explicam a natureza desse espaço e colocam em contato pessoas com pessoas, pessoas com projetos, e projetos com projetos. São realizadas convocatórias abertas para a apresentação de propostas e participação ativa no desenvolvimento desses projetos. Há um programa de atividades composto por oficinas de produção e formação, seminários e debates, reuniões de diferentes 
grupos de trabalho, mostras de projetos, conferências e outros eventos, como concertos e performances.

A programação se estrutura em linhas estáveis de trabalho: Interativas (usos criativos da eletrônica e da programação); Inclusiva.net (pesquisa e reflexão acerca da cultura das redes); Visualizar (estratégias e ferramentas de visualização da informação); Laboratório do Pró-Comum (discussão transdisciplinar sobre os bens comuns); AVLAB (criação sonora e audiovisual). As atividades, em sua maioria, são registradas e retransmitidas em vídeo, e posteriormente podem ser consultadas e descarregadas pela web.

No caso da gestão 2003-2010 do Ministério da Cultura brasileiro (MinC), percebe-se a busca da incorporação da tecnologia digital às políticas públicas culturais, mas procurando entender o computador e a internet como pontos de partida, e não como objetivos finais em si (congregando a inclusão digital à inclusão social, numa perspectiva similar a de Warschauer, 2006) Dessa forma, o MinC priorizou não tanto a infraestrutura tecnológica, mas o potencial de transformação suscitado pelos novos paradigmas de produção, circulação e consumo cultural. Ao incentivar práticas de compartilhamento, debate, articulação e trabalho colaborativo, procurou-se ampliar as possibilidades de ressonância de expressões culturais, historicamente limitada nos meios de comunicação de massa tradicionais, criando perspectivas inéditas para o acesso à informação e ao conhecimento. Dentro desse espírito, o MinC formulou sua primeira iniciativa voltada para a cultura digital: a proposta de implantação de estúdios digitais de produção audiovisual, conectados à internet e utilizando software livre nos Pontos de Cultura, no âmbito do Programa Cultura Viva. Denominada Ação Cultura Digital, a iniciativa procurava potencializar a rede formada pelos Pontos de Cultura. (ALMEIDA, 2014)

O MinC estabeleceu como diretriz para suas ações três pilares conceituais: autonomia, protagonismo e empoderamento, que se relacionariam também a três dimensões da cultura, a simbólica, a cidadã e a econômica. A proposta dos Pontos de Cultura seguia essa filosofia, e invertia a lógica de atuação do Estado: em vez de levar ações culturais prontas para as comunidades, são estas que definem as práticas que desejam fortalecer, com reconhecimento e apoio do governo. Esta ação se concretiza no apoio a projetos de espaços culturais, denominados Pontos de Cultura, selecionados por editais públicos ou em parcerias com estados, municípios e redes dos pontos. Sem a exigência de um modelo único de atividades, 
programação ou instalações físicas, os Pontos de Cultura têm em comum, desde seu lançamento, além da gestão compartilhada entre poder público e comunidade, a presença em diversos deles, de um estúdio digital multimídia. A rede é também incentivada pelos Pontões Digitais, criados pelo MinC a partir de $2007^{1}$. O público contemplado por esta iniciativa inclui tanto quem participa diretamente das atividades desenvolvidas nos projetos culturais, quanto integrantes da comunidade, que assistem às apresentações artísticas ou participam de cursos e oficinas. Vale atentar para o caráter de processo, e não de produto ou serviço, que marca a iniciativa: o MinC dava, portanto, centralidade não à infraestrutura tecnológica, mas ao caráter de transformação suscitado pelas novas possibilidades de expressão e de produção cultural, bem como de circulação dessa produção no ciberespaço, de construção de uma cultura de rede e de usufruto dessa conexão para um semnúmero de objetivos. (ALMEIDA, 2014).

Mas nem tudo são flores em relação à implantação dessa política. Os aspectos educativos da mediação - a capacitação dos sujeitos envolvidos no uso das tecnologias -, mostrou-se, em larga medida, o calcanhar de Aquiles da iniciativa. Na avaliação realizada pelo IPEA (SILVA; ARAÚJO, 2010, p. 68) com os atores dessa experiência, a política proposta pelo MinC foi encarada como muito importante, mas também foram apontados muitos problemas, entre eles, as dificuldades de acompanhamento, assistência técnica inadequada e outros fatores de complicação relacionados ao uso de ferramentas/softwares livres (por exemplo, a inadequação de algumas delas para uso no campo artístico, em especial no campo audiovisual). A falta de intimidade com o sistema operacional LINUX, somada a falta de suporte efetivo por parte do MINC, levou alguns dos pontos optarem por usar o Windows. Enfatize-se que em alguns estados os Pontões ou outros pontos foram indicados como capazes de fazer uso e realizar capacitação adequada nos termos da proposta do Programa Cultura Digital. Mas esse processo foi seletivo e insuficiente, já que outros pontos desses mesmos estados criticaram os processos e

\footnotetext{
${ }^{1}$ Há duas principais diferenças entre os pontos e os pontões. A primeira diz respeito à natureza dos projetos: enquanto os pontos de cultura realizam ações diretas nas comunidades, com interferência na dinâmica local própria dos grupos, espera-se que os pontões de cultura, por sua vez, tenham o perfil de articuladores, formadores de rede e atuação mais macro, em um conjunto determinado de pontos de cultura que pode ser organizado por temática ou por região. A outra diferença refere-se à instituição proponente, seu perfil de atuação e capacidade de agenciamento: como os pontões de cultura têm característica de formadores e articuladores, é fundamental que possuam estrutura material e humana suficiente para transitar entre esses diferentes pontos de cultura.
} 
a abrangência dessa capacitação. Por outro lado, essa realização "enviesada" dos objetivos da política, mesmo não cumprindo o script proposto (ao utilizar um software proprietário no lugar de um software livre) nos remete à dinâmica estabelecida por Michel de Certeau (1994) entre o emprego de estratégias e o emprego de táticas.

A realidade dos pontos de cultura é muito diversa justamente porque a lógica do Programa Cultura Viva opera com base no apoio a associações socioculturais que já desempenhavam um papel na sociedade mais ampla ou em comunidades locais e específicas. Assim, cada projeto de ponto de cultura apresentado pela sociedade civil é estruturado em cima de demandas próprias, necessidades diferentes, que estão diretamente ligadas ao perfil e à capacidade de articulação da organização proponente. Ao atuar com base nessa lógica, a heterogeneidade é algo que necessariamente se faz presente e tem reflexo imediato na análise do programa, tornando muito difícil tecer generalizações simplesmente a partir de seu arcabouço institucional "oficial". Existe nos pontos de cultura uma diferença crucial em sua capacidade de operação e agenciamento que está ligada a um conjunto de fatores, normalmente, vinculados ao desenvolvimento institucional da organização que o abriga e da capacidade de articulação dos atores envolvidos. (ALMEIDA, 2014)

No caso das iniciativas espanholas relatadas, embora os processos de mediação educativa pareçam ter atingido um maior grau de maturidade, foi possível perceber dificuldades relacionadas ao contexto econômico, que apontavam para a dificuldade de obtenção de recursos necessários à preservação e continuidade dessas iniciativas. Idem para o caso brasileiro, que sofreu desgaste semelhante na transição de governo. No período da gestão da ministra Ana de Hollanda (2011/2012), o que se pode observar foi uma descontinuidade em relação às políticas anteriores de integração e inclusão cultural por meio da internet e tecnologias digitais, compreendendo a discussão de direitos autorais, livre circulação de material cultural pelas redes e formação e capacitação de agentes culturais via Telecentros e Pontões Culturais. Mesmo com a substituição da ministra em questão, em agosto de 2012, pela senadora Marta Suplicy, a retomada do programa, especialmente no que tange aos repasses de verba que viabilizam essas iniciativas, não foi plenamente cumprida ainda. 


\section{CONSIDERAÇÕES FINAIS}

As conexões entre cultura e tecnologia se tornam cada vez mais estreitas, e não podem mais ser analisadas de forma ingênua. Como o Janus da mitologia grega, a tecnologia nos sonda com sua dupla face: de um lado, um horizonte de potencialidades a se explorar; de outro, caminhos e possibilidades que sutil e desapercebidamente se fecham. As observações desenvolvidas anteriormente, a partir de Pariser (2012) e os "filtros invisíveis", são ilustrativas acerca desse último ponto.

Assim, ao refletirmos sobre as atividades de mediação no contexto contemporâneo dos fluxos tecnoculturais, não procuramos fazer uma apologia ao mundo digital e às TICs, mas de fazer constar que sua presença, mesmo que problemática, enriquece e disponibiliza novos meios e recursos para a apropriação da informações e conhecimentos, assim como para a expressão e criação cultural, dinamizando as relações sociais. Essas considerações, ainda por amadurecer, apontam para o fato de que o grau de autonomia e as condições socioculturais dadas para a apropriação da informação e dos usos culturais das tecnologias variam contextualmente. $\mathrm{O}$ encontro de indivíduos e de grupos com as instituições merece ser compreendido como um processo complexo povoado por práticas heterogêneas e não excludentes. A apropriação social da informação, dos conhecimentos e da tecnologia não é um processo simples e linear. As práticas e políticas culturais de mediação brevemente discutidas apontam para essa complexidade, ilustrando como a construção de processos de mediação cultural voltados para o empoderamento dos atores enfrenta dificuldades de distintas naturezas para tentar se enraizar socialmente. Nesse sentido, vale relembrar a lição de Michel de Certeau (1994), ao apontar não as restrições impostas pelos aparatos aos indivíduos, mas a criatividade das práticas sociais, para voltarmos nosso olhar para a apropriação das tecnologias e das informações nos processos vivos de produção e circulação da cultura.

Ao levantarmos alguns aspectos relacionados à discussão em torno do termo Humanidades Digitais, procuramos na verdade compreendê-lo como mais que uma etiqueta genérica, e sim como sintoma de uma discussão maior que envolve a aproximação entre os campos das ciências humanas e sociais, as tecnologias e as mediações. Nesse sentido, elas reatualizam, sob novos olhares e contextos, a velha oposição entre as "duas culturas" tratadas por Snow. Na nossa percepção, ao se 
postularem como um território interdisciplinar de mediações disposto a dar guarida às reflexões e às práticas suscitadas pelas mudanças decorrentes da introdução das tecnologias digitais no universo da cultura, as Humanidades Digitais também apontam para outra questão: a circulação e a apropriação do conhecimento, e o papel social que pode ser desempenhado pelas universidades e pelos pesquisadores nesse processo.

\section{AGRADECIMENTOS:}

O autor agradece aos colegas da Universidade Carlos III de Madrid, em especial a Tony Hernandez e Vírgínia Ortíz-Repiso Jiménez, pela convivência que permitiu conversar e refletir acerca de muitas das questões levantadas no texto. Ao CNPq e à FAPESP, pelo apoio em diferentes momentos da pesquisa.

\section{REFERÊNCIAS}

ALMEIDA, Marco A. Mediações da cultura e da informação: perspectivas sociais, políticas e epistemológicas. Tendências da Pesquisa Brasileira em Ciência da Informação v. 1, $n^{\circ} 1,2008$.

Habermas e as apropriações culturais das TICs: rumo a ciberesferas públicas? Problemata: R. Intern. Fil. Vol. 03. Nº. 02, pp. 127-156, 2012.

Políticas culturais e redes sociotécnicas: reconfigurando o espaço público. Revista Ciências Sociais Unisinos, São Leopoldo, Vol. 50, N. 1, p. 54-64, jan/abr 2014.

BURKE, Peter. Uma história social do conhecimento. Rio de Janeiro, Zahar, 2008.

. Uma história social do conhecimento II: da enciclopédia à Wikipedia. Rio de Janeiro, Zahar, 2012.

CALLON, Michel. Por uma nova abordagem da ciência, da inovação e do mercado: o papel das redes sociotécnicas. In: PARENTE, André (org.) Tramas da rede: novas dimensões filosóficas, estéticas e políticas da comunicação. Porto Alegre: Sulina, p. 64-79, 2004.

CASTELLS, Manuel. Internet e sociedade em rede. In: MORAES, Denis de (org.) Por uma outra comunicação: mídia, mundialização cultural e poder. Rio de Janeiro: Record, p. 255-287, 2003. 
CAUNE, Jean. Cultura e comunicação: convergências teóricas e lugares de mediação. São Paulo: Ed. UNESP, 2014.

CERTEAU, Michel de. A invenção do cotidiano: 1. artes de fazer. Petrópolis (RJ): Vozes, 1994.

DAVALLON, Jean. A mediação: a comunicação em processo? Revista Prisma.Com, n. 4, p. 03-36, 2007.

DOUEIHI, Milad. La gran conversión digital. Buenos Aires: Fondo de Cultura Económica, 2010.

FLEURY, Laurent. Sociologia da cultura e das práticas culturais. São Paulo: SENAC, 2009.

FOURIE, Ina. ¿Debemos tomarnos en serio la desintermediación? Anales de Documentación: Revista de Biblioteconomía y documentación, Murcia, vol. 4, p. 267-282, 2001.

GALINA-RUSSELL, Isabel. ¿Qué son lasHumanidadesDigitales? Revista Digital Universitaria, v. 12 n. 7, México, UNAM, julio/2011.

GIORDANO, R. B.; BIOLCHINI, J. C. A. Busca e recuperação da informação científica na web: comportamento informacional de profissionais da informação. Revista INCID vol. 3, n. 1, p. 125-146, 2012.

HABERMAS, Jürgen. Mudança estrutural na esfera pública. Rio de Janeiro: Tempo Brasileiro, 1984. 1989.

Consciência moral e agir comunicativo. Rio de Janeiro: Tempo Brasileiro,

HALL, Stuart. A centralidade da cultura: notas sobre as revoluções culturais do nosso tempo. Educação \& Realidade, Porto Alegre, v. 22, ํㅡㄹ, p. 15-46, 1997.

A identidade cultural na pós-modernidade. Rio de Janeiro: DP\&A, 2005.

HERNÁNDEZ-PÉREZ, Tony; GARCÍA-MORENO, María Antonia. Los retos de la alfabetización informacional en las bibliotecas: guía para superar la brecha entre nativos e inmigrantes digitales. Revista Prisma.Com, n. 13, p. 01-20, 2010.

LATOUR, Bruno. Reensamblar lo social: una introducción a la teoría del actorred. Buenos Aires: Manantial, 2008.

LÉVY, Pierre. A revolução contemporânea em matéria de comunicação. In: MARTINS, F. M.; SILVA, J. M. da (orgs.) Para navegar no século XXI: tecnologias do imaginário e cibercultura. Porto Alegre: Sulina, p. 195-216, 2000.

MELUCCI, Alberto. A invenção do presente: movimentos sociais nas sociedades complexas. Petrópolis, RJ: Vozes, 2010. 
MIĖGE, Bernard. A sociedade tecida pela comunicação: técnicas da informação e da comunicação entre inovação e enraizamento social. São Paulo: Paulus, 2009.

OUTHWAITE, William; BOTTOMORE, Tom (eds). Dicionário do pensamento social do século XX. Rio de Janeiro: Jorge Zahar, 1996.

PARISER, Eli. O filtro invisível: o que a internet está escondendo de você. RJ: Jorge Zahar, 2012.

PONS, Anaclet. El desorden digital: guía para historiadores y humanistas. Madrid: Siglo XXI, 2013.

POSTMAN, Neil. Tecnopólio - A rendição da Cultura à Tecnologia. São Paulo: Nobel, 1994.

SANTAELLA, Lúcia. Navegar no ciberespaço: o perfil cognitivo do leitor imersivo. São Paulo: Paulus, 2004.

SILVA, F. A. B.; ARAÚJO, H. E. Cultura Viva: avaliação do Programa Arte Educação e Cidadania. Brasília: IPEA, 2010.

SVENSSON, Patrik. The Landscape of Digital Humanities. Digital Humanities Quarterly, vol. 4, n. 1, 2010.

WARSCHAUER, Mark. Tecnologia e inclusão social: a exclusão digital em debate. São Paulo: Senac, 2006.

WOLTON, Dominique. Internet, e depois? Uma teoria crítica das novas mídias. Porto Alegre: Sulina, 2003.

YÚDICE, George. A conveniência da cultura: usos da cultura na era global. Belo Horizonte: UFMG, 2006.

\section{Title}

Mediation and mediators in the contemporary technocultural flows

\section{Abstract}

Introduction: The Information and Communication Technologies have established a global network in which societies with different lifestyles and stories intertwine, causing a profound impact on everyday ways of life of individuals. Follows from this new challenges to think about the actions of mediation information - particularly in hybrid territory characterized by the coexistence and intersection of cultural \& technological processes.

Objective: Analyze the social changes related to the plot of contemporary informational and cultural practices, seeking to understand aspects of cultural processes and the social rootedness of technology. Map some challenges for mediation today, involving technological, cultural and political issues. Discuss the field of Digital Humanities as a new field of mediation.

Methodology: Literature review, field observations. 
Results: classical and contemporary discussions on the subject, and also the discussion intermediation versus disintermediation are presented. Some mediation actions are presented as input for reflection.

Conclusion: The connections between culture and technology become increasingly narrow, and cannot be analyzed naively. The term Digital Humanities, although it is still a generic label, appears as a interdisciplinary field willing to give shelter to the reflections and practices raised by the changes arising from the introduction of digital technologies in the world of culture and in the Cultural and Information Units.

Key words: Mediation. Culture. Information and Communication Technology. Digital Humanities.

\section{Título}

La mediación y los mediadores en los flujos tecnoculturales contemporáneos

\section{Resumen}

Introducción: Las Tecnologías de Información y Comunicación han establecido una red mundial en la que las sociedades con diferentes estilos de vida y historias se entrelazan, causando un profundo impacto en las formas cotidianas de vida de los individuos. Sobreviene de ahí desafíos sin precedentes para pensar en las acciones de información de la mediación - particularmente en ese territorio híbrido que se caracteriza por la coexistencia y la intersección de los procesos culturales y tecnológicos.

Objetivo: Analizar los cambios sociales relacionados con el campo de las prácticas informativas y culturales contemporáneos, buscando comprender aspectos de los procesos culturales y el arraigo social de la tecnología. Mapear algunos retos para la mediación actual, en relación con cuestiones de tecnología, cultura y política. Discutir el campo de las Humanidades Digitales como un nuevo campo de la mediación.

Metodología: revisión de la literatura, observaciones de campo.

Resultados: Se presentan discusiones clásicas y contemporáneas sobre el tema, así como la discusión intermediación frente a la desintermediación. Algunas acciones de mediación se presentan como elementos para la reflexión.

Conclusiones: Las conexiones entre la cultura y la tecnología son cada vez más estrechas, y no pueden ser analizadas con ingenuidad. El término Humanidades Digitales, aunque todavía es una etiqueta genérica, aparece como un campo interdisciplinario dispuesto a dar cobijo a las reflexiones y prácticas planteadas por los cambios derivados de la introducción de las tecnologías digitales en el mundo de la cultura y de las Unidades de Información y Cultura.

Palabras clave: La mediación y los mediadores en los flujos tecnoculturales contemporáneos.

Recebido em: 15.07.2014

Aceito em: 05.10.2014 